\title{
OTIMIZAÇÃO E VALIDAÇÃO DE MÉTODO PARA DETERMINAÇÃO DE ÁCIDOS ORGÂNICOS EM VINHOS POR CROMATOGRAFIA LÍQUIDA DE ALTA EFICIÊNCIA
}

\author{
Luciana L. de Andrade Lima*, Alexandre Schuler e Nonete Barbosa Guerra \\ Departamento de Nutrição, Centro de Ciência da Saúde, Universidade Federal de Pernambuco - Campus Universitário, \\ 50670-901 Recife - PE, Brasil \\ Giuliano Elias Pereira \\ Embrapa Uva Vinho/Semi-Árido, CP 23, 56302-970 Petrolina - PE, Brasil \\ Taciana L. de Andrade Lima \\ Organização Trajetória Mundial, Rua Eng. Ubaldo Gomes de Matos, 53, 50010-907 Recife - PE, Brasil \\ Helena Rocha \\ Unidade de Vigilância Agropecuária Internacional - Complexo Industrial Portuário de SUAPE, Rod. PE-60, km 10, Ipojuca - PE, Brasil
}

Recebido em 31/7/09; aceito em 13/1/10; publicado na web em 23/4/10

\begin{abstract}
OPTIMIZATION AND VALIDATION METHOD FOR ORGANIC ACID DETERMINATION IN WINES BY HIGH PERFORMANCE LIQUID CROMATOGRAPHY. The organic acids (tartaric, malic, citric, lactic and succinic) are de main components responsible for the acidity in the wine. This method for simultaneous determination of organic acids and interfering peaks in wines can be achieved in $16 \mathrm{~min}$. The sample preceded by a dilution and filtration step. The chromatographic separation required one reversed phase column, isocratic mobile phase (acetonitrila, formic acid in water) and detection wavelength was set at $212 \mathrm{~nm}$. The validation confirmed good repeatability, recovery and application in red and white wines.
\end{abstract}

Keywords: organic acids; wines; HPLC UV/Vis.

\section{INTRODUÇÃO}

Os ácidos orgânicos ocorrem naturalmente nos alimentos como resultado de processos metabólicos, bioquímicos, hidrólises e crescimento bacteriano. Nos vinhos, estes ácidos, provenientes da uva (tartárico, málico e cítrico) e dos processos de fermentação alcoólica e malolática (lático e succínico), Figura 1, contribuem com a cor, aroma, gosto, características e equilíbrio gustativo e para a estabilidade microbiológica e química. ${ }^{1-7}$<smiles>O=C(O)C(O)C(O)C(=O)O</smiles>

Ácido Tartárico<smiles>O=C(O)CC(O)C(=O)O</smiles>

Ácido Málico<smiles>O=C(O)CC(O)(CC(=O)O)C(=O)O</smiles>

Ácido Cítrico

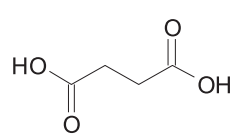

Ácido Succínico
Figura 1. Estruturas químicas dos ácidos tartárico, málico, lático, cítrico e succínico

Dentre eles, os principais são os ácidos tartárico, málico e cítrico. O ácido tartárico da uva é o isômero L(+), sendo a videira um dos poucos vegetais onde este ácido está presente em quantidades elevadas. ${ }^{6}$ O isômero L(-) do ácido málico, encontrado nas folhas e frutos, é um dos mais difundidos na natureza e possui pouca resistência à oxidação, enquanto seu precursor, o ácido cítrico, está presente nas raízes. ${ }^{6,7}$

\footnotetext{
*e-mail: lucianalima.ufrpe@gmail.com
}

O ácido lático, produzido durante a fermentação malolática, confere suavidade gustativa, e o ácido succínico é um subproduto da fermentação alcoólica. ${ }^{4}$

A uva é responsável por mais de $95 \%$ dos atributos percebidos no vinho. Seus ácidos orgânicos apresentam, entretanto, variações nas concentrações na dependência da variedade, grau de maturação do fruto, disponibilidade de água e temperatura - decorrente da exposição ao sol. Apesar desses compostos serem mais resistentes do que outros componentes do vinho, como pigmentos e aromáticos, apresentam mudanças no seu teor em função dos processos tecnológicos de vinificação - maceração, maceração pelicular - e envelhecimento. ${ }^{2,4,5}$

No vinho, a acidez pode ser determinada através da acidez real (expressa pelo $\mathrm{pH}$ ), acidez titulável e concentração individual de cada ácido. $\mathrm{O}$ pH depende, principalmente, do tipo e concentração dos ácidos orgânicos, além da concentração de cátions, especialmente de potássio $\left(\mathrm{K}^{+}\right)$, que precipitam o ácido tartárico na forma de sal insolúvel de bitartarato de potássio. . $^{8-10}$

Dentre as várias técnicas usadas na identificação e quantificação dos ácidos orgânicos em vinhos, podemos citar espectrofotometria, eletroforese capilar e cromatografia., ${ }^{2,46}$ Entretanto, a cromatografia líquida de alta eficiência (CLAE) é a mais usada na identificação individual destes compostos, devido a sua simplicidade, precisão, facilidade de preparação das amostras, envolvendo apenas etapas de diluição e filtração, e menor custo da análise. ${ }^{4,7,8}$ Os métodos disponíveis na literatura utilizam para esta determinação comprimentos de onda entre 210 e $212 \mathrm{~nm}$, coluna de sílica C-18, fase móvel menos corrosiva possível, com pH máximo de 2,5, e injeção de amostras de vinho diluídas e filtradas. , $^{2,7-9,11-14}$

Dong ${ }^{12}$ determinou os ácidos orgânicos por CLAE a $210 \mathrm{~nm}$, utilizando gradiente de tampão fosfato e acetonitrila, com coluna C-18, similar ao preconizado pelo método da $\mathrm{OIV}^{13}$ exceto quanto à fase móvel (para os ácidos cítrico e lático solução de ácido sulfúrico $0,0125 \mathrm{~mol} \mathrm{~L}^{-1}$ e para os ácidos tartárico, málico e succínico solução com fosfato monoácido de potássio e sulfato de amônio em $\mathrm{pH}$ 2,1). Rizzon e Miele ${ }^{14}$ mantiveram 
a coluna C-18, entretanto utilizaram comprimento de onda de $212 \mathrm{~nm}$ e solução aquosa de ácido fosfórico (pH 2,5) como fase móvel.

As diferenças entre os métodos, principalmente com relação à fase móvel, motivaram a realização deste trabalho com o objetivo de selecionar, otimizar e validar um método a ser utilizado para determinação dos ácidos orgânicos em vinhos finos, tintos e brancos.

\section{PARTE EXPERIMENTAL}

\section{Reagentes e soluções analíticas}

Os padrões utilizados, com grau de pureza superior a $99,0 \%$, foram ácido tartárico, ácido L-(-)-málico e ácido cítrico, Merck ${ }^{\circledR}$, e ácidos lático e succínico Vetec ${ }^{\circledR}$, dos quais foram preparadas soluções aquosas (água ultrapura, Milli-Q, Millipore ${ }^{\circledR}$ ), com as seguintes concentrações: ácido tartárico, 50,0 mg mL $\mathrm{mL}^{-1}$; ácidos málico e lático, 100,0 mg mL ${ }^{-1}$; ácidos cítrico e succínico, 25,0 mg $\mathrm{mL}^{-1}$. Com a mistura destas soluções obteve-se uma solução única com concentração de ácido tartárico, $5,0 \mathrm{mg} \mathrm{mL}^{-1}$; ácidos málico e lático, $10,0 \mathrm{mg} \mathrm{mL}^{-1}$; e, ácidos cítrico e succínico, $1,0 \mathrm{mg} \mathrm{mL}^{-1}$. Todas as soluções foram armazenadas a $6{ }^{\circ} \mathrm{C}\left( \pm 1^{\circ} \mathrm{C}\right)$.

A fase móvel foi preparada pela mistura de ácido fosfórico, $0,12 \%, \mathrm{e}$ acetonitrila grau HPLC, $0,1 \%$, em água ultrapura (Milli-Q, Millipore ${ }^{\circledR}$ ).

\section{Instrumentação e condição cromatográfica}

A separação cromatográfica foi realizada em cromatógrafo a líquido Ultimate 3000 Dionex $^{\circledR}$ equipado com bomba isocrática (3000 pump), detector de absorção molecular (3000 RP variable wavelength detector), compartimento para columa (3000 column compartiment), coluna analítica Acclaim ${ }^{\circledR} 120$ Dionex C-18 $(250$ x 4,6 mm, $5 \mu \mathrm{m})$, sistema manual de injeção com volume fixo de $20 \mu \mathrm{L}$ e sistema de aquisição de dados através do software Chromeleon $^{\circledR}$.

No método otimizado foi mantido o comprimento de onda de 212

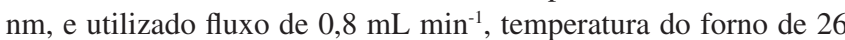
${ }^{\circ} \mathrm{C}$, volume de injeção de $20 \mu \mathrm{L}$ e tempo total de corrida de $16 \mathrm{~min}$.

\section{Estabilidade dos padrões analíticos e da fase móvel}

A mistura de padrões na concentração intermediária - ácido tartárico, 0,5 $\mathrm{mg} \mathrm{mL}^{-1}$; ácidos málico e lático, $1,0 \mathrm{mg} \mathrm{mL}^{-1} \mathrm{e}$ ácidos cítrico e succínico, $0,1 \mathrm{mg} \mathrm{mL}^{-1}$ - e a fase móvel foram armazenados sob refrigeração, por 4 semanas, e avaliados a cada 2 dias por meio de injeções, em triplicata.

Os resultados foram tratados estatisticamente por análise de variância e a diferença entre as médias calculada pelo teste de Dunnett ao nível de 5\% (Excel for Windows). A avaliação da fase móvel foi realizada por observação do perfil cromatográfico, com relação à capilaridade e simetria dos picos.

\section{Validação do método}

Após definidas as melhores condições cromatográficas e a fase móvel para análise dos ácidos orgânicos, foi efetuada a validação do método abrangendo os seguintes parâmetros:

\section{Seletividade}

Determinada mediante adição da mistura dos ácidos nas concentrações de ácido tartárico, $0,20 \mathrm{mg} \mathrm{mL}^{-1}$; ácidos málico e lático, $0,40 \mathrm{mg} \mathrm{mL}^{-1} \mathrm{e}$ ácidos cítrico e succínico, $0,04 \mathrm{mg} \mathrm{mL}^{-1} \mathrm{em}$ amostra de vinho tinto (Petit verdot) e branco (Verdejo), e os resultados cromatográficos avaliados em função do tempo de retenção e resolução dos analitos.

\section{Linearidade}

A faixa de linearidade foi estabelecida através da injeção de 5 concentrações diferentes obtidas por diluições, em água ultrapura, da mistura contendo os cinco ácidos orgânicos, conforme segue: ácido tartárico, 0,025 a 1,0 $\mathrm{mg} \mathrm{mL}^{-1}$; ácidos málico e lático, 0,05 a 2,0 mg mL $\mathrm{m}^{-1} \mathrm{e}$ ácidos cítrico e succínico, 0,01 a $0,2 \mathrm{mg} \mathrm{mL}^{-1}$. A curva analítica para cada ácido orgânico foi obtida por correlação entre concentração e área, através do modelo linear dos mínimos quadrados (Chromeleon ${ }^{\circledR}$ ).

Limite de detecção do instrumento (LDI) e limite de quantificação do instrumento (LQI)

Ambos foram determinados por injeção de diluições da mistura, contendo os cinco ácidos, até concentração correspondente à razão sinal/ruído de 3 e 10 para LDI e LQI, respectivamente. ${ }^{2}$

\section{Precisão}

A repetibilidade do instrumento e do método foi avaliada por meio do coeficiente de variação (CV \%) das áreas obtidas de 7 injeções da mistura aquosa (ácido tartárico, $0,5 \mathrm{mg} \mathrm{mL}^{-1}$; ácidos málico e lático, $1,0 \mathrm{mg} \mathrm{mL}^{-1} \mathrm{e}$ ácidos cítrico e succínico, $0,1 \mathrm{mg} \mathrm{mL}^{-1}$ ) e dos vinhos adicionados com esta mistura, respectivamente. Na avaliação da precisão intermediária utilizaram-se 5 injeções, em dias diferentes, da mistura aquosa dos ácidos e as áreas obtidas foram comparadas por análise de variância (ANOVA) e teste de Dunnett ao nível de 5\% (Excel for Windows).

\section{Exatidão}

Foi estabelecida a partir da recuperação de três fortificações, em vinhos tinto e branco, com concentrações de ácido tartárico, 0,1, 0,5 e 1,0 mg mL $\mathrm{m}^{-1}$; ácidos málico e lático, 0,2, 1,0 e 2,0 mg mL $\mathrm{mL}^{-1} \mathrm{e}$ ácidos cítrico e succínico, 0,02, 0,1 e $0,2 \mathrm{mg} \mathrm{mL}^{-1}$. Os ensaios foram realizados em triplicata e as médias comparadas percentualmente com os valores teóricos.

\section{Robustez}

Foi avaliada através da variação de $10 \%$ no fluxo e na temperatura do forno, fase móvel preparada em balão volumétrico e em proveta, e leituras em comprimentos de onda de 191 e $233 \mathrm{~nm}$. Em cada condição estabelecida foi injetado em duplicata o ponto de concentração intermediária (ácido tartárico, $0,5 \mathrm{mg} \mathrm{mL}^{-1}$; ácidos málico e lático, $1,0 \mathrm{mg} \mathrm{mL}^{-1} \mathrm{e}$ ácidos cítrico e succínico, $0,1 \mathrm{mg} \mathrm{mL}^{-1}$ ) e avaliado quanto à sensibilidade e resolução dos analitos.

\section{Preparação das amostras de vinho}

As amostras de vinhos finos varietais tintos - Bonarda e Syrah - e brancos - Chenin Blanc, Moscato canelli e Sauvignon Blanc - comercializados na região metropolitana da cidade de Recife, PE, foram diluídas a $10 \%$ com água ultrapura e filtradas a $0,45 \mu \mathrm{m}$.

\section{RESULTADOS E DISCUSSÃO}

Após realização de ensaios com os métodos de Dong, ${ }^{12}$ OIV,${ }^{13}$ Escobal ${ }^{8}$ e Rizzon e Miele, ${ }^{14}$ selecionou-se este último tendo por critério a resolução dos analitos na análise cromatográfica. Em seguida, as condições cromatográficas foram otimizadas para o sistema em uso mediante controle da temperatura do forno $\left(26^{\circ} \mathrm{C}\right)$ e ajuste do fluxo $\left(0,8 \mathrm{~mL} \mathrm{~min}^{-1}\right)$. Para a fase móvel foram testadas concentrações decrescentes de ácido fórmico, de 1 a $0,12 \%$ e esta adicionada de acetonitrila para se obter um aumento da polaridade. Nestas condições foi obtida a melhor separação entre os ácidos orgânicos, em especial entre os ácidos cítrico e succínico e entre este e o interferente (tempo 
de retenção 14,5 min), conforme Figura 2. Convém ressaltar que o interferente, proveniente do padrão de ácido L-(-)-málico, tem sido observado em cromatogramas obtidos com o padrão isolado.

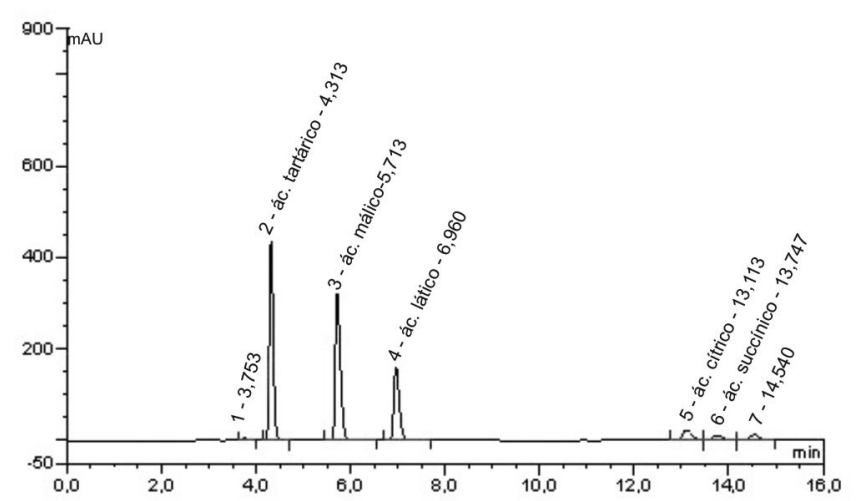

Figura 2. Cromatograma da mistura de ácido tartárico, $0,5 \mathrm{mg} \mathrm{mL}^{-1}$; ácidos málico e lático, 1,0 $\mathrm{mg} \mathrm{mL}^{-1}$ e ácidos cítrico e succínico, 0,1 $\mathrm{mg} \mathrm{mL}^{-1}$, com identificação dos compostos por nome e tempo de retenção

A seletividade do método foi satisfatória para todos os ácidos orgânicos, pelo aumento proporcional das áreas mediante adição da mistura dos ácidos orgânicos. Além disto, os tempos de retenção individuais destes ácidos apresentaram coeficientes de variação máximos de $0,5 \%$, em 10 injeções, inferior ao encontrado por Kerem. ${ }^{11}$

Os dados de linearidade da curva analítica, limites de detecção e quantificação do instrumento, e exatidão do método, cujos resultados foram expressos em recuperação percentual, encontram-se dispostos na Tabela 1. Nela verifica-se que a curva analítica, nas condições otimizadas, apresentou linearidade nas faixas de concentrações estudadas, com coeficientes de determinação $\left(\mathrm{r}^{2}\right)$ superiores a 0,999 , que evidenciam o ajuste das correlações na regressão linear. Ademais, a variação dos tempos de retenção e áreas foi inferior a 5\%, nas 5 repetições de cada nível de concentração, demonstrando repetibilidade instrumental.

Os resultados obtidos neste trabalho para os limites de detecção e quantificação do instrumento diferem dos obtidos por Zheng et $a l{ }^{2}$ - concentrações mais baixas no LDI e LQI e faixa de linearidade superior para os ácidos em estudo. Resultados semelhantes nas faixas de linearidade foram obtidos por Kritsunanhul et al. ${ }^{4}$ que, no entanto, obtiveram limites de detecção superiores para os mesmos analitos. Estas diferenças, provavelmente decorrentes do método empregado, não interferem nos resultados de amostras reais, uma vez que os vinhos apresentam concentrações mais elevadas de ácidos orgânicos.

Os resultados da exatidão nas concentrações estudadas, similares aos valores de exatidão obtidos por Zheng et $a l .^{2}$ - 89,1 a 108,8\% - são considerados satisfatórios por estarem dentro dos limites aceitos para validação de métodos cromatográficos, 70 a $120 \%$ de recuperação. ${ }^{15}$

Na Tabela 2 estão dispostos os resultados da precisão do instrumento e do método cromatográfico. Os valores de repetibilidade do instrumento e do método encontram-se abaixo dos limites máximos aceitos na validação de métodos cromatográficos, 5 e $15 \%$, respectivamente, semelhantes, portanto, aos descritos por Kerem et al. ${ }^{11}$ que relataram repetibilidade das áreas dos picos cromatográficos inferiores a 5\%. A comparação entre as áreas dos analitos nas análises realizadas em dias diferentes não apresentou variação significativa $(\mathrm{p}<0,01)$ para todos os ácidos orgânicos, o que demonstra a precisão intermediária do instrumento. ${ }^{15}$

A robustez de um método avalia a sua sensibilidade a pequenas e deliberadas alterações. ${ }^{16}$ Variações na preparação da fase móvel e de $10 \%$ na temperatura do forno e do fluxo da fase móvel não interferiram $(\mathrm{p}<0,01)$ nas respostas dos ácidos orgânicos, diferentemente das alterações do comprimento de onda. Convém ressaltar que as leituras
Tabela 1. Resultados obtidos dos parâmetros de validação para os analitos estudados

\begin{tabular}{|c|c|c|c|c|c|c|c|c|c|}
\hline \multirow{3}{*}{ Analitos } & \multirow{2}{*}{\multicolumn{2}{|c|}{$\begin{array}{l}\text { Limites do } \\
\text { Instrumento } \\
\left(\mathrm{mg} \mathrm{L}^{-1}\right)\end{array}$}} & \multirow{3}{*}{$\begin{array}{c}\text { Faixa linear, } \\
\mathrm{mg} \mathrm{L}^{-1}\left(\mathrm{r}^{2}\right)\end{array}$} & \multicolumn{6}{|c|}{ Exatidão (recuperação\%) } \\
\hline & & & & \multicolumn{3}{|c|}{ VB } & \multicolumn{3}{|c|}{ VT } \\
\hline & LD & LQ & & 1 & 2 & 3 & 1 & 2 & 3 \\
\hline Ácido tartárico & 2,6 & 13,0 & $\begin{array}{c}50-1.000 \\
(0,9998)\end{array}$ & 107 & 104 & 106 & 112 & 115 & 108 \\
\hline Ácido málico & 4,2 & 20,9 & $\begin{array}{c}100-2.000 \\
(0,9995)\end{array}$ & 101 & 99 & 104 & 114 & 109 & 107 \\
\hline Ácido lático & 4,7 & 31,6 & $\begin{array}{c}100-2.000 \\
(0,9994)\end{array}$ & 105 & 105 & 109 & 113 & 114 & 107 \\
\hline Ácido cítrico & 5,4 & 7,3 & $\begin{array}{l}10-200 \\
(0,9991)\end{array}$ & 113 & 112 & 84 & 97 & 100 & 103 \\
\hline Ácido succínico & 5,4 & 7,2 & $\begin{array}{l}10-200 \\
(0,9992)\end{array}$ & 101 & 109 & 85 & 106 & 106 & 111 \\
\hline
\end{tabular}

VB: vinho branco; VT: vinho tinto. 1: ác. tartárico $0,10 \mathrm{mg} \mathrm{mL}^{-1}$, ác. málico e lático $0,20 \mathrm{mg} \mathrm{mL}^{-1}$, ác.cítrico e succínico $0,02 \mathrm{mg} \mathrm{mL}^{-1} ; 2$ : ác. tartárico $0,25 \mathrm{mg} \mathrm{mL}^{-1}$, ác. málico e lático $0,50 \mathrm{mg} \mathrm{mL}^{-1}$, ác.cítrico e succínico 0,05 $\mathrm{mg} \mathrm{mL}^{-1}$; 3: ác. tartárico $0,50 \mathrm{mg} \mathrm{mL}^{-1}$, ác. málico e lático $1,00 \mathrm{mg} \mathrm{mL}^{-1}$, ác.cítrico e succínico $0,10 \mathrm{mg} \mathrm{mL}^{-1}$

Tabela 2. Resultados da repetibilidade do instrumento e do método

\begin{tabular}{lccc}
\hline Analitos & $\begin{array}{c}\text { Repetibilidade } \\
\text { instrumento }(\mathrm{CV} \%)\end{array}$ & $\begin{array}{c}\text { Repetibilidade método (CV \%) } \\
\text { VB* }\end{array}$ & VT* \\
\hline Ácido tartárico & 1,12 & 1,41 & 0,40 \\
Ácido málico & 1,35 & 0,90 & 5,50 \\
Ácido lático & 1,97 & 2,85 & 0,30 \\
Ácido cítrico & 0,43 & 1,82 & 3,60 \\
Ácido succínico & 1,52 & 6,93 & 1,07 \\
\hline
\end{tabular}

VB: vinho branco; VT: vinho tinto; CV \%: coeficiente de variação percentual; *concentrações: ác. tartárico $0,50 \mathrm{mg} \mathrm{mL}^{-1}$, ác. málico e lático $1,00 \mathrm{mg} \mathrm{mL}^{-1}$, ác.cítrico e succínico $0,10 \mathrm{mg} \mathrm{mL}^{-1}$

de área a $233 \mathrm{~nm}$ demonstraram perda de sensibilidade para todos os compostos em estudo, e a $191 \mathrm{~nm}$ apresentaram acréscimo de sensibilidade para o ácido tartárico e decréscimo para o ácido succínico.

As soluções e a fase móvel foram estáveis por 20 dias, o que pode ser observado pela diminuição na altura dos picos e na eficiência de separação da fase móvel nos cromatogramas (Figuras 3 e 4).

Os vinhos brasileiros analisados apresentaram concentrações de ácido lático superiores aos demais ácidos, conforme a Tabela 3. Estes resultados são comparáveis aos obtidos por Zheng ${ }^{2}$ - ácido lático, 3,4 $\mathrm{g} \mathrm{L}^{-1} \mathrm{e}$ ácido tartárico, $2,5 \mathrm{~g} \mathrm{~L}^{-1}$ - para vinhos finos tintos australianos, país com características edafoclimáticas semelhantes às do Brasil.

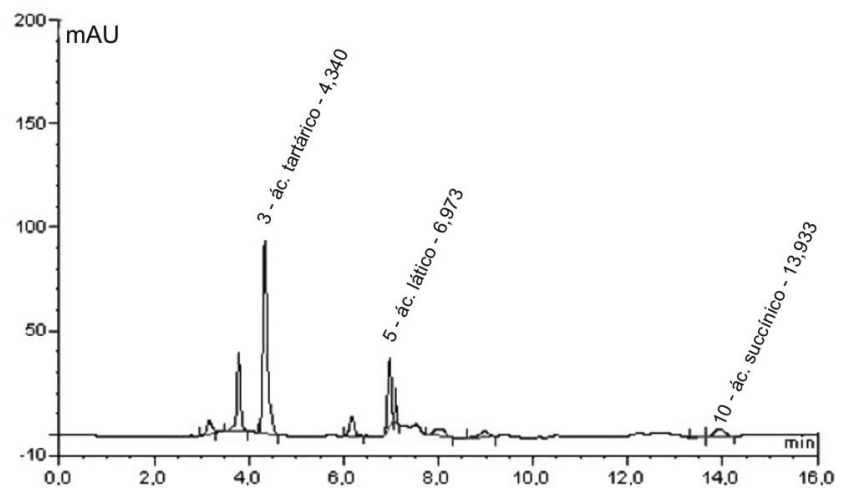

Figura 3. Cromatograma de vinho branco da variedade Verdejo, com identificação dos compostos por nome e tempo de retenção 


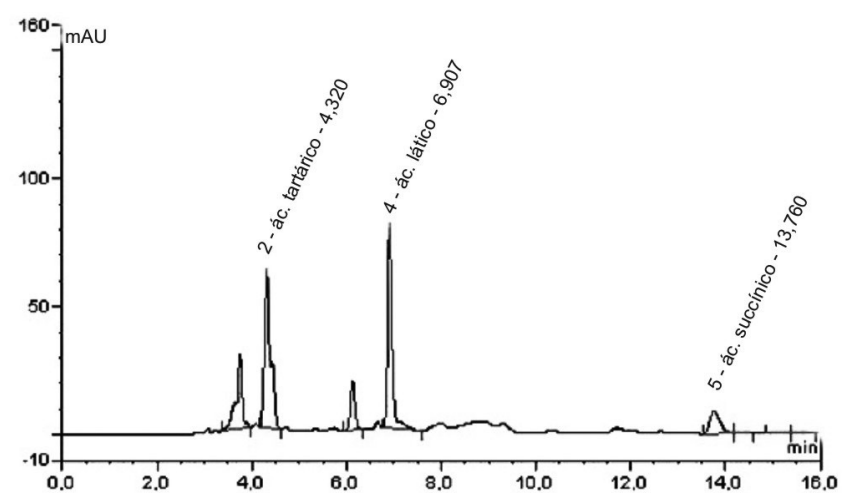

Figura 4. Cromatograma de vinho tinto da variedade Petit verdot, com identificação dos compostos por nome e tempo de retenção

Tabela 3. Concentrações dos ácidos orgânicos (tartárico, málico, lático, cítrico e succínco) em amostras de vinhos tintos e brancos comercializados em Recife/PE

\begin{tabular}{|c|c|c|c|c|c|}
\hline \multirow[b]{2}{*}{ Descrição do vinho } & \multicolumn{5}{|c|}{ Concentrações em $\mathrm{g} \mathrm{L}^{-1}$} \\
\hline & $\begin{array}{l}\text { Ácido } \\
\text { tartárico }\end{array}$ & $\begin{array}{l}\text { Ácido } \\
\text { málico }\end{array}$ & $\begin{array}{l}\text { Ácido } \\
\text { lático }\end{array}$ & $\begin{array}{l}\text { Ácido } \\
\text { cítrico }\end{array}$ & $\begin{array}{r}\begin{array}{r}\text { Ácido } \\
\text { succínico }\end{array} \\
\end{array}$ \\
\hline $\begin{array}{l}\text { Vinho tinto - Bonarda, } \\
\text { 2007, Argentina }\end{array}$ & 6,5 & ND & 7,1 & 0,8 & 1,4 \\
\hline $\begin{array}{l}\text { Vinho tinto - Syrah, } \\
\text { 2003, Brasil }\end{array}$ & 2,0 & 0,4 & 4,5 & ND & 3,0 \\
\hline $\begin{array}{l}\text { Vinho branco - Chenin } \\
\text { Blanc, 2008, Brasil }\end{array}$ & 1,0 & ND & 6,6 & 0,6 & 0,4 \\
\hline $\begin{array}{l}\text { Vinho branco - Moscato } \\
\text { canelli, 2007, Brasil }\end{array}$ & 1,4 & ND & 4,6 & 0,5 & 1,0 \\
\hline $\begin{array}{l}\text { Vinho branco - Moscato } \\
\text { canelli, 2008, Brasil }\end{array}$ & 2,3 & ND & 7,1 & 0,8 & 1,4 \\
\hline $\begin{array}{l}\text { Vinho branco - Sauvi- } \\
\text { gnon Blanc, 2007, Chile }\end{array}$ & 2,0 & 1,8 & 0,2 & 0,4 & ND \\
\hline
\end{tabular}

ND - não detectado

\section{CONCLUSÕES}

O método analítico utilizado pode ser aplicado para determinação de ácidos orgânicos, com rapidez (16 min) e facilidade de preparação das amostras. A otimização da fase móvel pela adição de acetonitrila possibilitou a melhoria da resolução cromatográfica de todos os ácidos; entretanto, aumentou a toxicidade. O método apresentou ótimos resultados em todas as etapas da validação - sensibilidade, precisão, exatidão e robustez, demosntrando a possibilidade de uma ampla utlização na análise de ácidos orgânicos em vinhos tintos e brancos.

\section{AGRADECIMENTOS}

Ao Conselho Nacional de Desenvolvimento Científico e Tecnológico $(\mathrm{CNPq})$ pelo suporte financeiro.

\section{REFERÊNCIAS}

1. Kallithraka, S.; Bakker, J.; Clifford, M. N.; J. Food Sci. 1997, 62, 416.

2. Zheng, Y. J.; Duan, Y. T.; Zhang, Y. F.; Pan, Q. H.; Li, J. M.; Huang, W. D. ; Chromatographia (2009), 69, 1 doi: 10.1365/s10337-009-1085-0.

3. Rizzon, L. A.; Salvador, M. B. G.; Miele, A.; Ciênc. Tec. Alim. 2008, 28, 635.

4. Kritsunankul, O.; Pramote, B.; Jakmunee, J.; Talanta 2009, 79, 1042.

5. Valentão, P.; Seabra, R. M.; Lopes, G.; Silva, L. R.; Martins, V.; Trujillo, M. E.; Velázquez, E.; Andrade, P. B.; Food Chem. 2007, 100, 64.

6. Fernandes, E. N.; Boaventura, F. R.; Anal. Chim. Acta 2006, 557, 380

7. Rizzon, L. A.; Sganzerla, V. M. A.; Ciênc. Rural 2007, 37, 911.

8. Rizzon, L. A.; Miele, A.; Ciênc. Rural 2001, 31, 893.

9. Escobal, A.; Iriondo, C.; Laborra, C.; Elejalde, E.; Gonzalez, I.; J. Chromatogr. 1998, 823, 349.

10. Daudt, C. E.; Fogaça, A. O.; Ciênc. Rural 2008, 38, 2345.

11. Kerem, Z.; Bravdo, B.; Shoseyov, O.; Tugendhaft, Y.; J. Chromatogr., A 2004, 1052, 211.

12. Dong, M. W.; LC-GC-The Magaz. of Separat. Sci. 1998, 10, 1092.

13. OIV - Organisation International de la Vigne et du Vin; Recueil des méthodes internationales d'analyse des vins et des moûts, 1990, p. 368.

14. Rizzon, L. A.; Miele, A.; Ciênc. Rural 2002, 32, 511.

15. Prestes, O. D.; Presta, M. A.; Kolberg, D. I. S.; Zanella, R.; Rossato, S. B.; Penna, N. G.; Hecktheuer, L. H. R.; Quim. Nova 2007, 30, 18.

16. Fonseca, S. G. C.; Silva, L. B. L.; Castro, R. F.; Santana, D. P.; Quim. Nova 2004, 27, 157. 